\title{
Design and optimization of inductively coupled spiral square coils for bio-implantable micro-system device
}

\author{
Abdelghani Lakhdari, Nasr-Eddine Mekkakia-Maaza, Meriem Dekmous \\ Laboratoire des Microsystèmes et Systèmes Embarqués L.M.S.E, \\ Université des Sciences et de la Technologie d'Oran, Algérie
}

\begin{tabular}{l} 
Article Info \\
\hline Article history: \\
Received May 25, 2018 \\
Revised Nov 12, 2018 \\
Accepted Mar 4, 2019 \\
\hline Keywords: \\
Biomedical implants \\
Inductive coupling \\
Square inductors \\
Wireless transfer power
\end{tabular}

\section{Article Info}

Article history

Received May 25, 2018

Revised Nov 12, 2018

Accepted Mar 4, 2019

\section{Keywords:}

Biomedical implants

Wireless transfer power

\begin{abstract}
Due to the development of biomedical microsystems technologies, the use of wireless power transfer systems in biomedical application has become very largely used for powering the implanted devices. The wireless power transfer by inductive resonance coupling link, is a technic for powering implantable medical devices (IMDs) between the external and implanted circuits. In this paper we describe the design of an inductive resonance coupling link using for powering small bio-implanted devices such as implantable biomicrosystem, peacemaker and cochlear implants. We present the reduced design and an optimization of small size obtained spiral coils of a $9.5 \mathrm{~mm}^{2}$ implantable device with an operating frequency of $13.56 \mathrm{MHz}$ according to the industrial scientific-medical (ISM). The model of the inductive coupling link based on spiral square coils design is developed using the theoretical analysis and optimization geometry of an inductive link. For a mutual distance between the two coils at $10 \mathrm{~mm}$, the power transfer efficiency is about $79 \%$ with $R_{\text {load }}=300 \Omega$, coupling coefficient of 0.075 and a mutual inductance value of $2 \mu \mathrm{H}$. In comparison with previous works, the results obtained in this work showed better performance such as the weak inter coils distance, the hight efficiency power transfer and geometry.
\end{abstract}

Copyright $\odot 2019$ Institute of Advanced Engineering and Science. All rights reserved.

\section{Corresponding Author:}

Abdelghani Lakhdari,

Laboratoire des Microsystèmes et Systèmes Embarqués L.M.S.E,

Université des Sciences et de la Technologie d'Oran, Mohamed Boudiaf, USTO-MB,

BP 1505 El M'naouer, 31000 Oran, Algérie.

Email: abdelghani.lakhdari@univ-usto.dz

\section{INTRODUCTION}

The interest in biomedical implants became more attractive since they have found applications in various domains such as cardiac pacemakers [1], cochlear prostheses [2] and multichannel neural recording applications [3]. Wireless power transfer is an alternative solution, which offers an attractive power delivery scheme for biomedical implants by limiting the need for battery replacement. The inductive coupling link is a one of the popular techniques used for the realization of the wireless power transfer (WPT) system for powering the implanted devices [4].

In general, the structure of the inductive coupling link for bio-implanted devices consist of two coils: an external coil (primary coil), which is placed outside the human body and the internal coil (secondary coil), which is inside the human body at a short distance from the external coil [5] as shown in Figure 1.

The bio-implantable devices intended for the smallest possible size must be implanted according to the functional depth in the human biological tissue. Which is usually less than $10 \mathrm{~mm}$ from the depth, for example, implanted microsystems are placed between 1-4 mm of depth. Cochlear implants are placed between 3-6 mm of the depth, and for retinal implants, is necessary a depth of $5 \mathrm{~mm} \mathrm{[6].} \mathrm{Currently,} \mathrm{the} \mathrm{study}$ of a wireless power transfer system for bio-implantable devices focuses on the design and optimization of the coils [7]. 
In general, the implantation of Bio-implantable devices within the human body using magnetic coupling for short distance, suffers from many problems, such as coils size, mutual distance between the coils, loss of coupling and efficiency power transfer.

In this paper, optimal of an inductive link coupling based on spiral square coils geometry used in wireless power transfer system for Bio-implantable devices at $13.56 \mathrm{Mhz}$ is proposed, the dimensions geometries of the coils offer $22.5 \mathrm{~mm}$ of the mutual distance in the air. However, at a distance of $10 \mathrm{~mm}$ between the coils, the power transfer efficiency is $79 \%$.

This paper is organized as follows: Section 2 presents theoretical analysis of the resonance inductive link system for biomedical application, section 3 presents modeling and optimization of the Inductively Coupled Spiral Square Coils at 13.56 MHz, in section 4 simulation and discussion of results are presented.

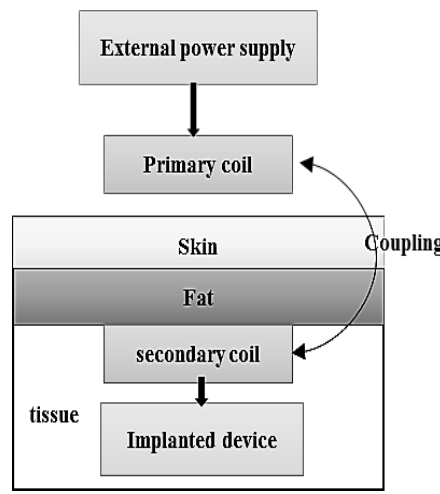

Figure 1. Inductive coupling link diagram of two coupled coils

\section{INDUCTIVE LINK FOR BIOMEDICAL IMPLANTABLE SYSTEMS}

\subsection{Resonance circuits in inductive coupling}

This section presents all circuits models topologies for inductive coupling systems for biomedical application, there are four different choices of resonant inductive coupling topologies: serial-to-parallel (SP), parallel to-serial (PS), serial-to-serial (SS) and parallel-to-parallel (PP) [8, 9], as shown in Figure 2, respectively. The mathematical models to calculate geometrical parameters of the coils and the wireless energy transfer efficiency for powering bio-implanted devices are presented. The systems composed of two coils, the primary coil is located outside the human body (external coil), and the secondary coil is located inside the human body (implanted coil) [10].
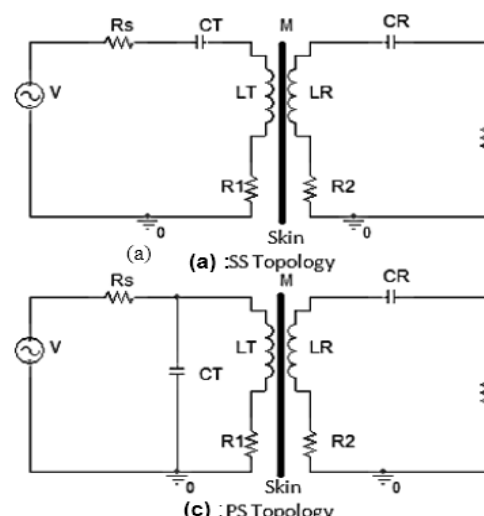

(c) : PS Topology

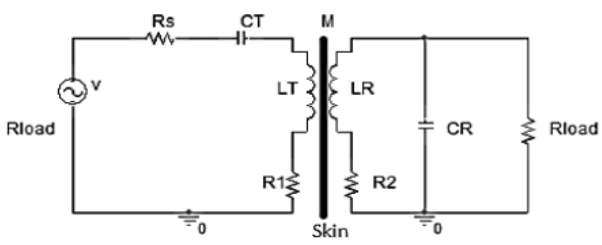

(b) : SP Topology

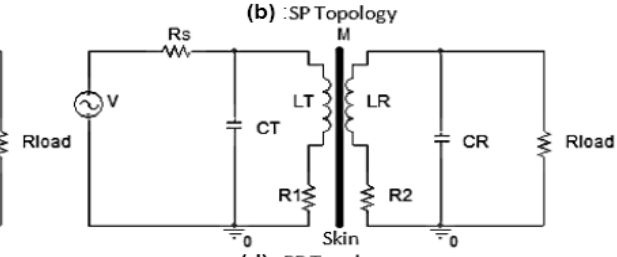

(d) : PP Topology

Figure 2. Four different topologies for inductive coupling systems

When $L_{T}$ and $L_{R}$ are self-inductance of the primary and secondary coils, respectively, $R_{1}$ and $R_{2}$ are the equivalent series resistance (parasitic resistance) of the primary and secondary coils, respectively, $R_{S}$ are the series resistance. The capacitors $C_{T}$ and $C_{R}$ are used to create a resonance on both sides of the link. 


\subsection{Inductive link resonant proposed}

The theoretical analysis and simulation are very important for designing a good ideal inductive link coupling for calculate and optimize the power transfer efficiency [11, 12]. In this part, we present the inductive link coupling with serial-to-parallel (SP) topology used for powering the implanted microsystems devices. Typically, the system consists of two resonant RLC circuits; the transmitter circuit (primary circuit), which represent the external circuit, and receiver circuit (secondary circuit) that represent the implanted circuit. We use the primary circuit in series resonance to provide a low impedance load, and the secondary circuit is almost invariably parallel. The operating resonance frequency is a bit $13.56 \mathrm{MHz}$; this frequency is selected according to industrial scientific and medical (ISM) band to avoid tissue heating [13]. Figure 3 shows SP inductive link coupling used for powering bio-implanted devices.

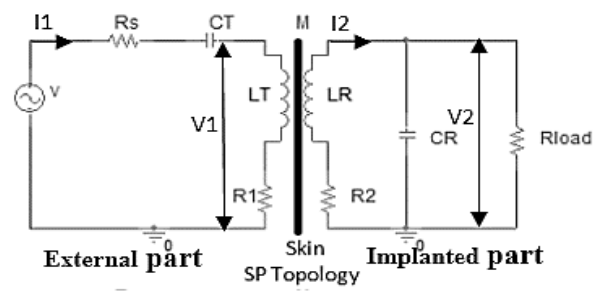

Figure 3. Inductive coupling link a series-to parallel

When $L_{T}$ and $L_{R}$ are the self-inductance of the external coil and implanted coil, respectively. The resistors $R_{1}, R_{2}$ represent the equivalent series resistance of the primary and secondary coils, respectively, $\left(C_{T}\right)$ and $\left(C_{R}\right)$ are the resonant capacitors in the external and implanted circuit, respectively, and $\mathrm{R}_{\text {load }}$ is the implanted resistance [14]. The load $\mathrm{R}_{\text {load }}$ represents the rectifier and additional power electronics. The degree of coupling between these two coils can be described in terms of their mutual inductance [15]. The mutual inductance between the external and implanted circuits defined by expression (1):

$$
\mathrm{M}=\mathrm{k} \sqrt{\mathrm{L}_{\mathrm{T}} \mathrm{L}_{\mathrm{R}}}
$$

The coupling factor $k$, shows the proportion of the external coil $\left(\mathrm{L}_{\mathrm{T}}\right)$ magnetic field, which is captured by the implanted coil $\left(\mathrm{L}_{\mathrm{R}}\right)$. Physically, $\mathrm{k}$ is equals to the fraction of the magnetic flux generated by the external coil $\mathrm{L}_{\mathrm{T}}$, which flows through the implant coil $\mathrm{L}_{\mathrm{R}}$; the coupling coefficient $\mathrm{k}$ is between zero and one and calculated as given in expression (2) [16]:

$$
\mathrm{k}=\frac{\mathrm{M}}{\sqrt{\mathrm{L}_{\mathrm{T}} \mathrm{L}_{\mathrm{R}}}}
$$

For the coupling coefficient $\mathrm{k}$ equals one, the coupling is at maximum, and for the coupling coefficient $\mathrm{k}$ equals zero, the two coils are uncoupled. The external inductance $\mathrm{L}_{\mathrm{T}}$ is calculated by expression (3):

$$
\mathrm{L}_{\mathrm{T}}=\frac{1}{\mathrm{C}_{\mathrm{T}} \omega_{0}^{2}}
$$

The Operating frequency $\omega_{0}=2 \pi f$. The internal inductance $L_{R}$ is calculated by expression (4):

$$
\mathrm{L}_{\mathrm{R}}=\frac{1}{\mathrm{C}_{\mathrm{R}} \omega_{0}^{2}}
$$

The series resistance of the implanted secondary coil is expressed by (5):

$$
\mathrm{R}_{2}=\frac{\mathrm{R}_{\text {load }}}{1+\omega_{0}^{2} \mathrm{R}_{\text {load }}^{2} \mathrm{C}_{\mathrm{R}}^{2}}
$$

Figure 4 represents the equivalent electrical model of the inductive link coupling (SP), the primary part is placed in the air; the secondary part is placed in the human body (implant part). 


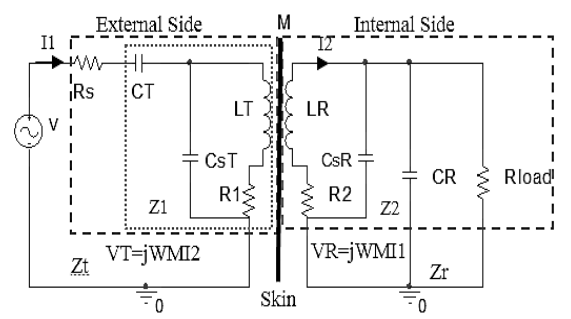

Figure 4. Simplified model of the resonant inductive coupling link

Each turn is equivalent to an inductor $\mathrm{L}$ in series with a resistance $\mathrm{R}$ and both in parallel to a capacitance. where $R_{1}$ and $R_{2}$ characterize the internal resistances of the inductance $L_{T} L_{R}$, respectively. $\mathrm{C}_{\mathrm{ST}}$ and $\mathrm{C}_{\mathrm{SR}}$ characterize their parasitic capacitances of the primary and secondary coils [17], respectively. In general, the electrical parameters $\left(Z_{t}\right.$ and $\left.Z_{r}\right)$ of an inductor depend on the frequency expressed by (6)-(9):

$$
\begin{aligned}
& Z_{\mathrm{t}}=\frac{v_{\mathrm{T}}}{\mathrm{I}_{1}}=\frac{\mathrm{w}^{2} \mathrm{M}^{2}}{\mathrm{Z}_{2}} \\
& \mathrm{Z}_{\mathrm{r}}=\frac{\mathrm{v}_{\mathrm{R}}}{\mathrm{I}_{2}}=j w M \frac{\mathrm{I}_{1}}{\mathrm{I}_{2}} \\
& \mathrm{Z}_{1}=\left(\mathrm{R}_{1}+j w L_{\mathrm{T}} / / \frac{1}{j w \mathrm{C}_{\mathrm{ST}}}\right)+\frac{1}{j w \mathrm{C}_{\mathrm{T}}} \\
& \mathrm{Z}_{2}=\mathrm{R}_{1}+j w L_{\mathrm{R}}+\frac{1}{j w \mathrm{C}_{\mathrm{R}}} / / \mathrm{R}_{\text {load }}
\end{aligned}
$$

According to the expression (10), we calculate the implanted load resistance $\mathrm{R}_{\text {load }}[18]$.

$$
\mathrm{R}_{\text {load }}^{2}-4 \mathrm{w}^{2} \mathrm{~L}_{\mathrm{R}}^{2}>0, \mathrm{w}=2 \pi \mathrm{f} \text { and } \mathrm{R}_{\text {load }} \geq 4 \pi f \mathrm{~L}_{\mathrm{R}}
$$

\section{MODELING OF PLANER SPIRAL SQUARE COILS}

\subsection{Inductance calculation}

Applying a magnetic field in the external coil will induce a current flowing in the implant coil. The value of the induced current is associated to both the external and implant coils $\mathrm{L}_{\mathrm{T}}$ and $\mathrm{L}_{\mathrm{R}}$. According to the (11), as calculated the value of the self-inductance for planer spiral square coil [19].

$$
\mathrm{L}=\frac{\mathrm{C}_{1} \mu_{0} \mathrm{n}^{2} \mathrm{~d}_{\mathrm{avg}}}{2}\left[\mathrm{l}_{\mathrm{n}}\left(\frac{\mathrm{C}_{2}}{\varphi}\right)+\mathrm{C}_{3} \varphi+\mathrm{C}_{4} \varphi^{2}\right]
$$

where $\mathrm{n}$ is a number of turns of the coil, $\mu_{0}=4 \pi \times 10^{-7} \mathrm{H} / \mathrm{m}$ is the magnetic permeability, $\mathrm{C}$ is the coefficient the geometrical layout of the square spiral inductor based on the values as $\mathrm{C}_{1}=1.27, \mathrm{C}_{2}=2.07$, $\mathrm{C}_{3}=0.18$ and $\mathrm{C}_{4}=0.13, \varphi$ is the factor of form, which changes from 0 , when all the turns are concentrated on the perimeter like filament coils, to 1 when the turns spiral all the way to the center of the coil [20]. The fill factors $\varphi_{\mathrm{T}}, \varphi_{\mathrm{R}}$ for external and implanted coils, respectvely, is calculated by the (12):

$$
\varphi_{\mathrm{T}}=\frac{\mathrm{d}_{\text {out. } \mathrm{T}}-\mathrm{d}_{\text {in. } \mathrm{T}}}{\mathrm{d}_{\text {out. } \mathrm{T}}+\mathrm{d}_{\text {in. } \mathrm{T}}}, \varphi_{\mathrm{R}}=\frac{\mathrm{d}_{\text {out } \mathrm{R}}-\mathrm{d}_{\text {in.R }}}{\mathrm{d}_{\text {out } \mathrm{R}}+\mathrm{d}_{\text {in.R }}}
$$

In addition, is the average diameter of coil $\mathrm{d}_{\mathrm{avg}}$, is calculated by (13):

$$
\mathrm{d}_{\text {avg.T }}=\frac{\left(\mathrm{d}_{\text {out.T }}+\mathrm{d}_{\text {in.T.T }}\right)}{2}, \mathrm{~d}_{\mathrm{avg} \cdot \mathrm{R}} \frac{\left(\mathrm{d}_{\text {out.R }}+\mathrm{d}_{\text {in.R }}\right)}{2}
$$

where $\mathrm{d}_{\text {out }}$ is outer diameter and $\mathrm{d}_{\mathrm{in}}$ inner diameters of the coil.

The outer diameters of the external and implant coils, is expressed by (14):

$$
\mathrm{d}_{\mathrm{out}}=\mathrm{d}_{\mathrm{in}}+2 \mathrm{wn}+2 \mathrm{~s}(\mathrm{n}-1)
$$

where $\mathrm{n}$ is a number of turns, $\mathrm{w}$ width of the conductor and $\mathrm{s}$ is the space between the turns. 
Figure 5 are shown all geometrics parameters of the square implanted coil. The optimized parameters value of the implanted and external coil is shown in Table 1. The optimization aims are to reduce the implanted coil geometrics.

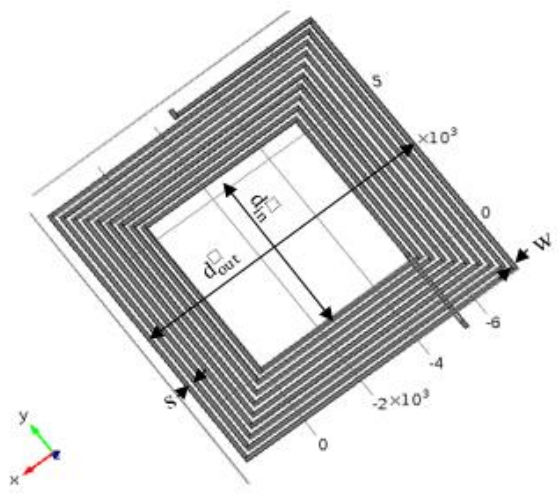

Figure 5. Planar spiral square coil

Table 1. The parameters value of the implant and external coils

\begin{tabular}{cccc}
\hline Quantity & Symbol & External coil & Implanted coil \\
\hline Outer diameter & $\mathrm{d}_{\text {out }}$ & $45 \mathrm{~mm}$ & $9.50 \mathrm{~mm}$ \\
Inner diameter & $\mathrm{d}_{\mathrm{in}}$ & $4.30 \mathrm{~mm}$ & $4.90 \mathrm{~mm}$ \\
Average Diameter & $\mathrm{d}_{\mathrm{avg}}$ & $24.65 \mathrm{~mm}$ & $7.20 \mathrm{~mm}$ \\
Inductance & $\mathrm{L}$ & $5,1 \mu \mathrm{H}$ & $1 \mu \mathrm{H}$ \\
Number of turns & $n$ & 15 & 9.50 \\
Inductor width & $\mathrm{w}$ & $0.98 \mathrm{~mm}$ & $0.15 \mathrm{~mm}$ \\
Turn spacing & $\mathrm{s}$ & $0.40 \mathrm{~mm}$ & $0.10 \mathrm{~mm}$ \\
Fill factor & $\varphi$ & 0.82 & 0.32 \\
Thickness of conductor & $\mathrm{t}_{\mathrm{c}}$ & $35 \mu \mathrm{m}$ & $35 \mu \mathrm{m}$ \\
\hline
\end{tabular}

\subsection{Coupling coefficient and mutual inductance calculation}

We consider two planer spiral square coils with outer diameters a and b. The mutual distance between external and implant coils should satisfy the condition in the expression (15):

$$
\mathrm{a}=\sqrt{\mathrm{X}^{2}+\mathrm{b}^{2}}
$$

where $\quad a=\frac{d_{\text {out.T }}}{2}, b=\frac{d_{\text {out.R }}}{2}$

Expression (16) proposed a simple ratio of the distance between the coils and outer diameter of the external coil to maximize the magnetic field in the receiving coil.

$$
\mathrm{d}_{\text {out.T }} \leq \mathrm{X} * 2 \sqrt{2}
$$

where $\mathrm{X}$ represents the maximum distance between the external and implant square spiral coils.

The mutual distance between the external and implant spiral square coils should satisfy the condition present in the (17) [21]:

$$
\frac{\mathrm{d}_{\text {out.T }}}{2}=\sqrt{\mathrm{X}^{2}+\left(\frac{\mathrm{d}_{\text {out.R }}}{2}\right)^{2}}
$$

For the two paralleled square coils with $\mathrm{n}_{T}$ and $\mathrm{n}_{\mathrm{R}}$ turns, respectively, separated by distance $\mathrm{X}$, the geometrical mutual inductance $\mathrm{M}$ between the external and implant coils can be calculated using (18):

$$
M=\frac{1}{2} \mu_{0} \sqrt{d_{\text {out.T }}^{2} \times d_{\text {out.R }}^{2}}\left[\left(\frac{2}{f}-f\right) K(f)-\frac{2}{f} E(f)\right]
$$

With $\mathrm{f}=\left(\frac{4 \times \mathrm{d}_{\text {out. } \mathrm{T}}^{2} \times \mathrm{d}_{\text {out. }}^{2}}{\left(\mathrm{~d}_{\text {out. } \mathrm{T}}^{2}+\mathrm{d}_{\text {out. } \mathrm{R}}^{2}\right)^{2}+\mathrm{X}^{2}}\right)^{\frac{1}{2}}$ 
where, $K(f)$ and $E(f)$ are elliptic integrals of the first and second order; respectively and $\mu_{0}$ is the permeability of the free space equal to $4 \pi \times 10^{-9} \mathrm{H} / \mathrm{cm}$ [22].

The geometrical approximation of the mutual inductance $M$ between the external and implanted spiral square coils is given by the expression (20):

$$
\mathrm{M}=\frac{\mu_{0} \mathrm{n}_{\mathrm{T}} \mathrm{d}_{\text {out. } \mathrm{T}}^{2} \mathrm{n}_{\mathrm{R}} \mathrm{d}_{\text {out. } \mathrm{R}}^{2} \pi}{2 \sqrt{\left(\mathrm{d}_{\text {out. }}^{2}+\mathrm{X}^{2}\right)^{3}}}
$$

According to the (1), the geometrical approximation of the coupling coefficient $\mathrm{K}$ between two square coils (external and implant coils) is determined by the distance between the two coils and calculated by $(21)$ :

$$
K=\frac{d_{\text {out } T}^{2} d_{\text {out.R }}^{2}}{\sqrt{d_{\text {out. } T}^{2} d_{\text {out.R }}^{2}\left(\sqrt{d_{\text {out } . T}^{2}+X^{2}}\right)^{3}}}
$$

\subsection{Resistance calculation}

The series resistance $R_{s}$ of the coil can be calculated using the following expression (22) [23]:

$$
\mathrm{R}_{\mathrm{s}}=\mathrm{R}_{\mathrm{dc}} \frac{\mathrm{t}_{\mathrm{c}}}{\delta\left(1-\mathrm{e}^{\frac{-\mathrm{t}_{\mathrm{c}}}{\delta}}\right)}
$$

where $\mathrm{R}_{\mathrm{dc}}$ is the $\mathrm{DC}$ electrical resistance of the coil as given in expression (23):

$$
\mathrm{R}_{\mathrm{dc}}=\rho_{\mathrm{c}} \frac{\mathrm{l}_{\mathrm{c}}}{\mathrm{wt}_{\mathrm{c}}}
$$

where $\rho_{c}$ is the resistivity of the material, $l_{c}$ is the total length of the material, and $w$ refers to the width of the material, $\mathrm{t}_{\mathrm{c}}$ is material thickness.

The total length of the copper coil is given by (24):

$$
l_{c}=4 n\left[d_{\text {out }}-(n-1) s-n w\right]-s
$$

where, $\mathrm{w}$ and $\mathrm{s}$ are the line width of the copper and the space within every turn, respectively. $\delta$ is the skin depth of the conductor as given in expression (25) [24].

$$
\delta=\sqrt{\frac{\rho_{\mathrm{c}}}{\pi \cdot \mu \cdot \mathrm{f}}} \text { with } \mu=\mu_{\mathrm{r}} \cdot \mu_{0}
$$

where $\mu_{0}=4 \pi \times 10^{-9} \mathrm{H} / \mathrm{cm}$ is the permeability of space, and $\mu_{\mathrm{r}}$ is the relative permeability of the material.

\subsection{Quality factor and link efficiency}

Power transfer efficiency to medical devices implant by inductive coupling link allows reducing the size of the transmitter power generated by external circuit [19]. The coupling coefficient $\mathrm{k}$ and the quality factor of the inductors are important parameters for calculated and maximize the power transfer efficiency of the implantable devices [25]. The qualities factors $Q_{T}$ and $Q_{R}$ of the coils related to the parasitic resistance and the inductance of the coils, can be calculated by (26):

$$
\mathrm{Q}_{\mathrm{T}}=\frac{\mathrm{w}_{0} \mathrm{~L}_{\mathrm{T}}}{\mathrm{R}_{1}}, \mathrm{Q}_{\mathrm{R}}=\frac{\mathrm{w}_{0} \mathrm{~L}_{\mathrm{R}}}{\mathrm{R}_{2}}
$$

where $\mathrm{w}_{0}=2 \pi \mathrm{f}_{0}$ is the angular frequency of resonance.

The resonant frequency of two circuits is given by (27):

$$
\mathrm{f}_{0}=\frac{1}{2 \pi\left(\mathrm{L}_{\mathrm{T}} \mathrm{C}_{\mathrm{T}}\right)^{\frac{1}{2}}}=\frac{1}{2 \pi\left(\mathrm{L}_{\mathrm{R}} \mathrm{C}_{\mathrm{R}}\right)^{\frac{1}{2}}}
$$

In this section, we present a simple and accurate method to calculate the power transfer efficiency. The maximum power transfer efficiency is obtained for maximum coupling coefficient and quality factor of 
the coils. Generally, the value of the coupling coefficient between the coils is very small. The total power transfer efficiency of the inductive coupling link is dominated by primary and implanted circuit's side efficiencies $\eta_{T}$ and $\eta_{R}$, respectively given by relation (28) [26].

$$
\eta_{T} \leq \frac{K^{2} Q_{T} Q_{R} R_{\text {load }}}{K^{2} Q_{T} Q_{R} R_{\text {load }}+Q_{R}^{2} R_{2}}, \eta_{R} \leq \frac{Q_{R}^{2} R_{2}}{Q_{R}^{2} R_{2}+R_{\text {load }}}
$$

The total power transfer efficiency of the system can be calculated by (29):

$$
\eta_{\text {total }}=\eta_{T} \eta_{R}=\frac{K^{2} Q_{T} Q_{R}^{3} R_{2} R_{\text {load }}}{\left(K^{2} Q_{T} Q_{R}^{3} R_{2} R_{\text {load }}+K^{2} Q_{T} Q_{R} R_{\text {load }}^{2}+Q_{R}^{4} R_{2}^{2}+2 Q_{R}^{2} R_{2} R_{\text {load }}+R_{\text {load }}^{2}\right)}
$$

where $K$ is the coupling coefficient and $Q_{T}, Q_{R}$ are qualities factors of the external and implant coils, respectively.

\section{RESULTS AND DISCUSSION}

In this application, the performance of the inductive coupling link based on the square spiral coils is designed, analysed and optimized. The position of the implanted coil in the tissue thickness is about $10 \mathrm{~mm}$, $1 \mathrm{~mm}$ for the skin (dry or wet), $2 \mathrm{~mm}$ for the fat and $7 \mathrm{~mm}$ for the muscle. The mutual distance of separation between external and implant coils is $10 \mathrm{~mm}$. According to the (17), we determine the relation between the distance and coils dimension proposed and presented in Figure 6, for a proposal geometry coil, the distance between coils is equivalent to $22.5 \mathrm{~mm}$ in the air. The factor coupling $\mathrm{K}$ is validated using (21). The relationship between coupling coefficient and separation distance of the coils can be obtained as shown in Figure 7, the coupling factor k decreases with the mutual distance between the external and implant coils. For the mutual distance between coils of $10 \mathrm{~mm}$, the coupling coefficient value is 0.075 .

Using the (20), we calculate the relation between the mutual inductance (M) and the mutual distance (X). Figure 8 shows the simulation of the mutual inductance values between the external and implant coils as a function of the mutual distance $(\mathrm{X})$, It's easy to see that mutual inductance decreases rapidly when axial distance is small. Equation (4) presents a formula by calculating based on MATLAB. The result of simulation is shown in Figure 9. For the distance between coils is around $10 \mathrm{~mm}$, the value of mutual inductance is $2 \mu \mathrm{H}$.

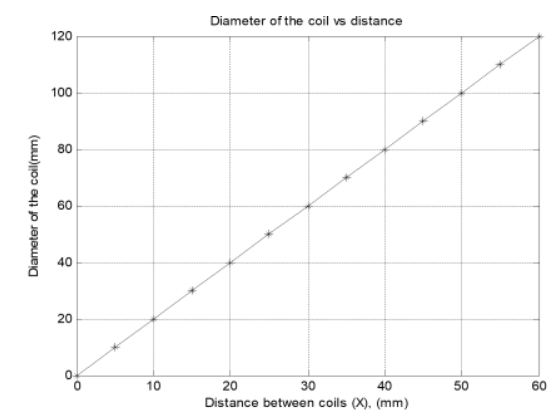

Figure 6. Diameter of the coil versus of the distance between external and implant coils $(\mathrm{X})$

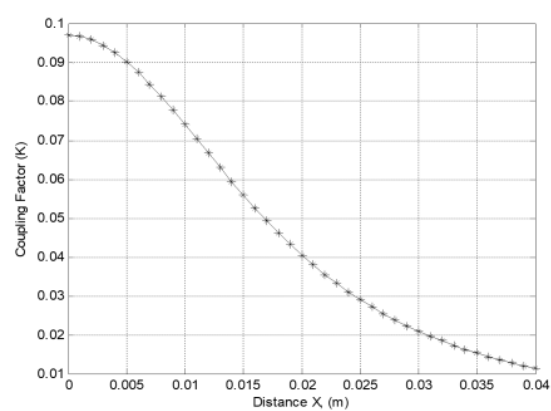

Figure 7. Coupling coefficient versus of the distance between external and implant coils $(\mathrm{X})$

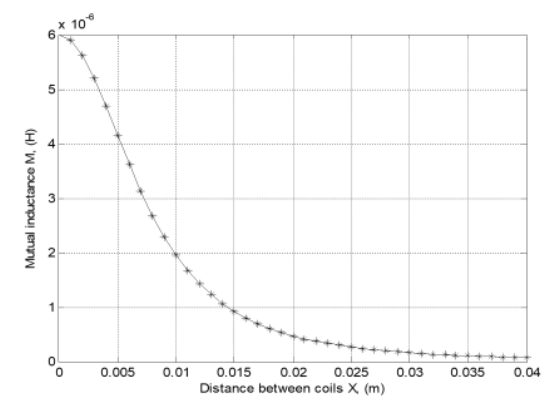

Figure 8. Mutual inductance versus of the distance between external and implanted coils (X) 


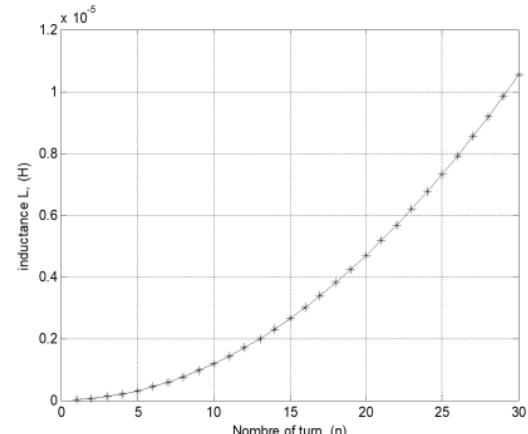

(a)

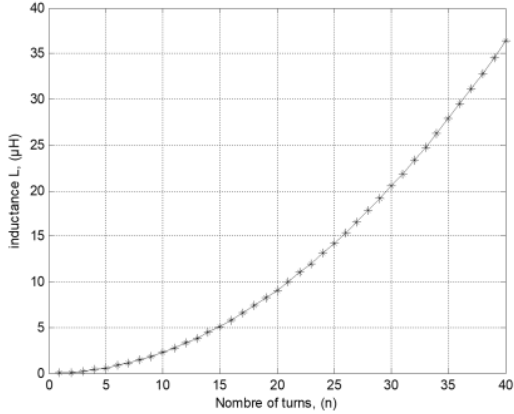

(b)

Figure 9. Inductance versus of the number turn (n) at (a) Primary coil $\left(\mathrm{d}_{\text {out.T }}=45 \mathrm{~mm}, \mathrm{~d}_{\text {in.T }}=4.3 \mathrm{~mm}\right)$

(b) Implanted coil $\left(\mathrm{d}_{\text {out.R }}=9.5 \mathrm{~mm}, \mathrm{~d}_{\mathrm{in.R}}=4.9 \mathrm{~mm}\right)$

The power transfer efficiency of the inductive coupling link is calculated and plotted versus these parameters using MATLAB; for validation of the inductive link efficiency, we proposed the values of the implanted loads $R_{\text {load }}$ which varies between $100 \Omega$ and $500 \Omega$. Figure 10 shows power transfer efficiency versus of the coupling distance and different values of $R_{\text {load }}$, respectively, at resonance frequency of 13.56 $\mathrm{MHz}$, The results show that the power transfer efficiency decreases proportionally with the increases of the resistance values $R_{\text {load }}$ it's varies between $73 \%$ and $86 \%$, for distance $\mathrm{X}=10 \mathrm{~mm}$ and $R_{\text {load }}=300 \Omega$. The maximum power efficiency is about $79 \%$, the external and implanted coils resistances are $\mathrm{R}_{1}=2.68 \Omega$, $\mathrm{R}_{2}=1.5 \Omega$, respectively. The coupling coefficient is 0.075 . The values of the quality factors of the external and implanted coils are $\mathrm{Q}_{\mathrm{T}}=255, \mathrm{Q}_{\mathrm{R}}=42.8$.According to the (29) we calculate the total power transfer efficiency.

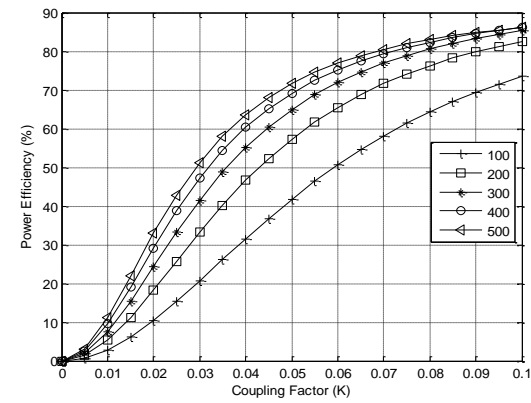

Figure 10. Power transfer efficiency versus of the coupling distance at resonance frequency of $13.56 \mathrm{MHz}$

Table 2 represents the obtained values of the proposed resonance inductive coupling link, $R \_l o a d$ is about $300 \Omega$ which is calculated according to the condition given by the expression (10), [ $\mathrm{R} \rrbracket[$ load $>170.4 \Omega$.

Table 2. The all parameters and value of the inductive link coupling

\begin{tabular}{lll}
\hline Description & Symbol & Value \\
\hline Primary Inductance & L_T & $5.1 \mu \mathrm{h}$ \\
Secondary Inductance & L_R & $1 \mu \mathrm{h}$ \\
Resistance Primary & R_1 & $2.68 \Omega$ \\
Resistance Secondary & R_2 & $1.5 \Omega$ \\
Primary Capacitance & C_T & $27 \mathrm{PF}$ \\
Secondary Capacitance & C_R & $137.76 \mathrm{PF}$ \\
Primary Quality Factor & Q_T & 255 \\
Secondary Quality Factor & Q_R & 42.8 \\
Load Resistance & R_load & $300 \Omega$ \\
Coefficient Coupling & K & 0.075 \\
Mutual Inductance & M & $2 \mu \mathrm{h}$ \\
Resonant Frequency & f_0 & $13.56 \mathrm{MHZ}$ \\
Power Efficiency & $\eta \_t o t a l$ & $79 \%$ \\
Distance & X & $10 \mathrm{~mm}$ \\
\hline
\end{tabular}


Figure 11 shows the flowchart of the geometrical design procedure of the external coil and the implanted coil of the energy transfer system. The procedure as seen in Figure 11 starts with a set of initial values of the external coil and the implanted coil and ends with the optimization of the geometry of two optimal coils which maximize the power transfer efficiency.

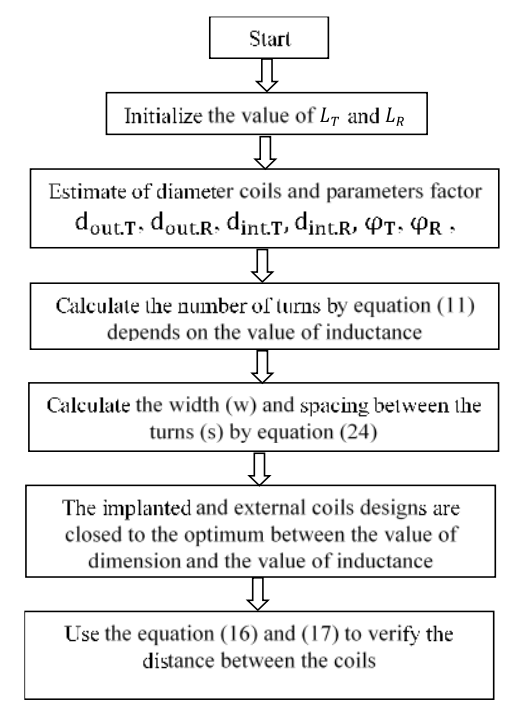

Figure 11. Flowchart of the geometrical design procedure of the coils

For verifying the parameters of the implanted coil, we compared our model with other models, this was carried out in this area, the comparison was being achieved according to several factors, including: the form of the coil, the dimensions of the coil, the operating frequency, the distance between the coils, as summarized in Table 3 .

Table 3. Comparison between the bio-implanted proposed coil design and other models

\begin{tabular}{|c|c|c|c|c|c|c|c|}
\hline & $\begin{array}{l}\mathrm{T}_{\mathrm{X}}-\text { Coil } \\
(\mathrm{mm})\end{array}$ & $\begin{array}{l}\mathrm{R}_{\mathrm{X}}-\text { Coil } \\
(\mathrm{mm})\end{array}$ & $\begin{array}{l}\text { Frequency } \\
(\mathrm{MHz})\end{array}$ & $\begin{array}{l}\text { Distance } \\
(\mathrm{mm})\end{array}$ & $\begin{array}{l}\text { Efficiency } \\
(\%)\end{array}$ & Applications & Ref \\
\hline square & $\begin{array}{l}\text { dout }=79 \\
\operatorname{din}=11.2\end{array}$ & $\begin{array}{l}\text { dout }=10 \\
\text { din }=2.96\end{array}$ & 13.56 & 10 & 52 & $\begin{array}{l}\text { Neuro } \\
\text { processing }\end{array}$ & [19] \\
\hline square & $\begin{array}{l}\text { dout }=38 \\
\text { din }=14.9\end{array}$ & $\begin{array}{l}\text { dout }=10 \\
\text { din }=5.8\end{array}$ & 13.56 & 10 & 72.2 & Neuroprosthetic & {$[27]$} \\
\hline $\begin{array}{l}\text { Tx-spiral coil } \\
\text { Rx-rectangular }\end{array}$ & dout $=44$ & $4 \times 8$ & 13.56 & 40 & _ & Subcutaneous tissue & {$[28]$} \\
\hline square & $(20 \times 20)$ & $(20 \times 20)$ & 915 & 15 & 65 & & [29] \\
\hline $\begin{array}{l}\text { Spiral } \\
\text { rectangular }\end{array}$ & $62 \times 25$ & $25 \times 10$ & 13.56 & 10 & 69 & Implanted microsystem & [30] \\
\hline square & $\begin{array}{l}\text { dout }=28 \\
\operatorname{din}=8\end{array}$ & $\begin{array}{l}\text { dout }=10 \\
\operatorname{din}=6\end{array}$ & 13.56 & 10 & 71.1 & - & {$[31]$} \\
\hline Spiral square & $70 \times 8$ & $20 x 8$ & $1-5$ & 10 & 75 & & {$[32]$} \\
\hline Spiral circular & $\begin{array}{l}\text { dout }=56 \\
\operatorname{din}=10\end{array}$ & $\begin{array}{l}\text { dout }=11.6 \\
\text { din }=5\end{array}$ & 13.56 & 6 & 73 & $\begin{array}{l}\text { Nerves and muscles } \\
\text { stimulator }\end{array}$ & [10] \\
\hline $\begin{array}{l}\text { Spiral } \\
\text { rectangular }\end{array}$ & $\begin{array}{l}\text { dout }=80 \\
\operatorname{din}=20\end{array}$ & $\begin{array}{l}\text { dout }=20 \\
\operatorname{din}=11\end{array}$ & 13.56 & 28 & 78 & - & {$[25]$} \\
\hline circular & 30 & $\begin{array}{l}\text { dout }=10 \\
\text { din }=4.3\end{array}$ & 13.56 & 10 & 55 & - & {$[33]$} \\
\hline square & $\begin{array}{l}\text { dout }=32 \\
\operatorname{din}=6.1\end{array}$ & $\begin{array}{l}\text { dout }=10 \\
\text { din }=5\end{array}$ & 13.56 & 10 & 73.46 & - & {$[34]$} \\
\hline square & $\begin{array}{l}\text { dout }=45 \\
\operatorname{din}=4.3\end{array}$ & $\begin{array}{l}\text { dout }=9.5 \\
\text { din }=4.9\end{array}$ & 13.56 & 10 & 79 & Implanted microsystem & $\begin{array}{l}\text { This } \\
\text { work }\end{array}$ \\
\hline
\end{tabular}

The results showed that the design we proposed has a smaller value of the dimensions of the implanted coil, which makes it quite suitable for implantation and a greater operational mutual distance. It can be seen that the power transfer efficiency obtained in this work is the highest as regards the distance between the coils and the size of the implanted coil. 


\section{CONCLUSION}

In this work we present an optimization by reducing the geometric dimensions of a pair of square spiral coils used for wireless power transfer in implanted biomedical devices. We studied the power transfer efficiency and the mutual distance as a function of reducing the geometry of the bio-implanted coil. The optimization of the geometry of the coils, allowed us to have values of the maximum power transfer efficiency equal to $79 \%$ and a distance between coils of $10 \mathrm{~mm}$.

This optimization allowed us to have geometric dimensions of the square implanted coil of surface area equal to $9.5 \mathrm{~mm}^{2}$ which is suitable for implantation in the human body. The results showed that the design we proposed has a smaller value of dimensions of the implanted coil, and a greater operational mutual distance which makes it quite suitable for implantation.

\section{REFERENCES}

[1] T. Sun, et al., "Wireless Power Transfer for Medical Microsystems," New York, Springer, 2013.

[2] K. Agarwal, et al., "Wireless Power Transfer Strategies for Implantable Bioelectronics: Methodological Review," IEEE reviews in biomedical engineering, vol. 10, 2017.

[3] S. B. Lee, et al., "A dual slope charge sampling analog front-end for a wireless neural recording system," $E M B C$, pp. 3134-3137, 2014.

[4] Supriyadi, et al., "Development of a Wireless Power Transfer Circuit Based on Inductive Coupling," TELKOMNIKA Telecommunication Computing Electronics and Control, vol/issue: 16(3), pp. 1013-1018, 2018.

[5] S. Hafiz, et al., "Resonant Configuration Topology Exploration for Inductive Link Power Transfer," Indonesian Journal of Electrical Engineering and Computer Science, vol/issue: 11(2), pp. 522-530, 2018.

[6] S. R. Khan and G. S. Choi, "Analysis and Optimization of Four-Coil Planar Magnetically Coupled Printed Spiral Resonators," Sensors, vol. 16, pp. 1219, 2016.

[7] A. K. R. Rakhyani and G. Lazzi, "On the Design of Efficient Multi-Coil Telemetry System for Biomedical Implants," IEEE transactions on biomedical circuits and systems, vol/issue: 7(1), pp. 11-23, 2013.

[8] N. Jamal, et al., "Investigations on Capacitor Compensation Topologies Effects of Different Inductive Coupling Links Configurations," International Journal of Power Electronics and Drive System (IJPEDS), vol/issue: 6(2), pp. 274-281, 2015.

[9] L.V. Ratio, et al., "Analysis and Comparison of Secondary Series and Parallel Compensated Inductive Power Transfer Systems Operating for Optimal Efficiency and Load-independent Voltage-Transfer Ratio," IEEE Trans. Power Electron., vol. X, pp. 1-12, 2013.

[10] S. Mutashar, et al., "Analysis and Optimization of Spiral Circular Inductive Coupling Link for Bio-Implanted Applications on Air and within Human Tissue," Sensors, vol. 14, pp. 11522-11541, 2014.

[11] M. A. Adeeb, et al., "An Inductive Link-Based Wireless Power Transfer System for Biomedical Applications," Active and Passive Electronic Components, 2012.

[12] M. Rehman, et al., "Modelling and Efficiency-Analysis of Wireless Power Transfer using Magnetic Resonance Coupling," Indonesian Journal of Electrical Engineering and Computer Science, vol/issue: 6(3), pp. 563-571, 2017.

[13] J. Wu, et al., "Wireless Power and Data Transfer via a Common Inductive Link Using Frequency Division Multiplexing," IEEE transactions on industrial electronics, 2015.

[14] S. Mehri, et al., "Geometry optimization approaches of inductively coupled printed spiral coils for remote powering of implantable biomedical sensors," Journal of sensors, 2016.

[15] M. K. Alghrairi, et al., "Optimization of spiral circular coils for bio-implantable micro-system stimulator at 6.78 mhz ism band," ARPN Journal of Engineering and Applied Sciences, vol/issue: 11(11), 2016.

[16] H. Ali, et al., "Inductive Link Design for Medical Implants," 2009 IEEE Symposium on Industrial Electronics and Applications (ISIEA 2009), Kuala Lumpur, Malaysia, 2009.

[17] H. Zhou, et al., "Modelling and Practical Implementation of 2-Coil Wireless Power Transfer Systems," Journal of Electrical and Computer Engineering, 2014.

[18] G. B. Hmida, et al., "Design of wireless power and data transmission circuits for implantable biomicrosystem," Biotechnology, vol/issue: 6(2), pp. 153-164, 2007.

[19] K. Yamaguchi, et al., "A General Method to Parameter Optimization for Highly Efficient Wireless Power Transfer," International Journal of Electrical and Computer Engineering (IJECE), vol/issue: 6(6), pp. 3217-3221, 2016.

[20] Harrison R., "Designing efficient inductive power links for implantable devices," Proceedings of IEEE Int. Conf. on circuits and systems (ISCAS), New Orleans, pp. 2080-2083, 2007.

[21] S. M. Abbas, et al., "Inductive coupling links for lowest misalignment effects in transcutaneous implanted devices," Biomed Tech, vol/issue: 59(3), pp. 257-268, 2014.

[22] D. C. Galbraith, et al., "A wide-band efficient inductive transdennal power and data link with coupling insensitive gain," IEEE Transactions on Biomedical Engineering, vol. 4, pp. 265-275, 1987.

[23] Y. L. Li and S. Sun, "Full-wave semi-analytical modeling of planar spiral inductors in layered media," Progress in Electromagnetics Research, vol. 149, pp. 45-54, 2014.

[24] H. Zenkner and W. K. Ngern, "Energy Transfer by Resonance Coupling," International Journal of Electricaland Computer Engineering (IJECE), vol/issue: 3(5), pp. 668-682, 2013. 
[25] S. Mehri, et al., "Genetic algorithm-based geometry, optimization of inductively coupled printed spiral coils for emote powering of electronic implantable devices," Computer \& Information Technology (GSCIT), pp. 1-6, 14-16, 2014.

[26] K. Yamaguchi, et al., "Using Square Wave Input for Wireless Power Transfer," International Journal of Electrical and Computer Engineering (IJECE), vol/issue: 6(1), pp. 431-438, 2016.

[27] Jow and M. Ghovanloo, "Modeling and optimization of printed spiral coils in air, saline, and muscle tissue environments," IEEE transactions on biomedical circuits and systems, vol/issue: 3(5), pp. 339-347, 2009.

[28] M. M. Ahmadi and G. A. Jullien, "A wireless implantable microsystem for continuous blood glucose monitoring," Biomedical Circuits and Systems, IEEE Transactions on., vol. 3, pp. 169-180, 2009.

[29] S. O'Driscoll, et al., "A mm-sized implantable power receiver with adaptive link compensation," 2009 IEEE International Solid-State Circuits Conference-Digest of Technical Papers, 2009.

[30] L. Andia, et al., "Closed loop wireless power transmission for implantable medical devices. In: Integrated Circuits (ISIC)," 2011 13th International Symposium on., pp. 404-407, 2011.

[31] Wu and Q. Fang, "Design and simulation of printed spiral coil used in wireless power transmission systems for implant medical devices," Engineering in Medicine and Biology Society, EMBC, 2011 Annual International Conference of the IEEE, pp. 4018-4021, 2011.

[32] M. Zargham and P. G. Gulak. "Maximum Achievable Efficiency in Near-Field Coupled Power Transfer Systems," Biomedical Circuits and Systems, IEEE Transactions on, vol. 6, pp. 228-245, 2012.

[33] Stocklin, et al., "Efficient Inductive Powering of Brain Implanted Sensors," Sensors Applications Symposium (SAS), IEEE, 2015. 